\title{
STRUCTURAL TRANSFORMATION OF OIL PALM MESOCARP FIBRE (OPMF) IN WATER AT SUBCRITICAL STATE
}

\author{
SANGGITHAPRIYA MAHANDRAN*; NORDIN SABLI*; MOHD HALIM SHAH ISMAIL*; HIROYUKI \\ YOSHIDA* and SHAMSUL IZHAR*
}

\begin{abstract}
Effect of subcritical water (sub-CW) on oil palm mesocarp fibre (OPMF) structure and cellulose conversion to obtain useful components was studied to reduce production of mesocarp fibre as waste in excessive amount. The decomposition of OPMF was carried out at temperatures ranging from $200^{\circ} \mathrm{C}-300^{\circ} \mathrm{C}$ and with a constant reaction time of 5 min using a batch stainless-steel tube reactor (reactor volume: $7.3 \mathrm{~cm}^{3}$ ). The pressure inside reactor was equal to the saturated vapour pressure at the experimental temperature. Microscope images indicated sub-CW broke down the OPMF walls becoming smaller particles. Scanning electron microcopy (SEM) images showed that the particle size of OPMF was highly porous when treated at $240^{\circ} \mathrm{C}$ but was disrupted when treated above $250^{\circ} \mathrm{C}$. From sugar analysis using high performance liquid chromatography (HPLC), the highest amount of monosaccharides was $22.2 \mathrm{mg} \mathrm{g}^{-1}$-dry OPMF at $240^{\circ} \mathrm{C}$. The yield of sugar was reduced to $2.5 \mathrm{mg} \mathrm{g}^{-1}-d r y$ OPMF at $300^{\circ} \mathrm{C}$ as cellulose and hemicellulose were degraded due to pyrolysis. The particle size of OPMF, when subjected to sub-CW, showed a good relationship with the yield of sugars. The OPMF particle became disrupted above $260^{\circ} \mathrm{C}$ due to the pyrolysis activity. The solid residue from OPMF was reduced significantly using sub-CW.
\end{abstract}

Keywords: oil palm mesocarp fibre (OPMF) structure, hydrolysis, subcritical water, lignocellulose.

Received: 18 March 2019; Accepted: 23 October 2019; Published online: 7 September 2020.

\section{INTRODUCTION}

Oil palm mesocarp fibre (OPMF) is known as lignocellulosic waste that consists of renewable sources such as carbohydrate sugars and useful chemical compounds that can be converted into value-added products (Iberahim et al., 2013). This lignocellulosic waste consists of cellulose, hemicelluloses and lignin at $32.2 \%, 31.6 \%$ and $23.9 \%$, respectively (Then et al., 2014). The ether and ester cross-link between cellulose and hemicellulose with the presence of lignin resulting in OPMF biomass to be classified as recalcitrant waste (Olanrewaju, 2012).

Department of Chemical and Environmental Engineering, Universiti Putra Malaysia,

43400 UPM Serdang, Selangor, Malaysia.

E-mail: shamizhar@upm.edu.my
OPMF, remained as waste after the extraction process, is collected and burned to produce steam to run generators in palm oil industries (Sreekala et al., 1997; Teoh, 2002). According to the National Innovation Agency Malaysia (2013), 9 million tonnes of OPMF will be produced annually as palm oil waste by 2020 . The amount of OPMF produced is more than needed by the oil palm industry to utilise its use to produce useful gases and power generation (Lau et al., 2008). An effective method in handling OPMF to recover reducing sugars and to treat the OPMF is required as an alternative to the burning process. Hence, subcritical water (sub-CW) technology was considered. Arrangement of molecules in cylindrical conformation structure with crystallites form and hydrogen bonds between microfibre layers make the cellulose formation stable (Yunos et al., 2012). The 
complex structure of palm oil cell causes difficulty in breaking down the cellulose using physical industrial-scale method (Kalsom et al., 1997; Ariffin et al., 2008).

The sub-CW region in the water phase diagram is located around its critical temperature $\left(374^{\circ} \mathrm{C}\right)$ and pressure at 22.1 MPa. High ion production and low relative dielectric constant at elevated temperature, hence, suitable for extraction of residual oil from OPMF. The dielectric constant of methanol, ethanol, and water are 32.5, 27.0 and 79.9, respectively, at room temperature (Amashukeli et al., 2007; Singh and Saldana, 2011; Yoshida et al., 2018). At sub-CW state, the dielectric constant value of water decreases from 79.9 to 17 as the temperature increases causing water to behave as an organic solvent (Pourali et al., 2009). Sub-CW behaves as acid and base catalyst as it can produce high ions at elevated temperature (Carr et al., 2011). At $250^{\circ} \mathrm{C}$, the ion production is at maximum due to the strong hydrolysis reaction. However, as the temperature increases from $250^{\circ} \mathrm{C}$, the pyrolysis reaction becomes active and reduces the ion production drastically (Pourali, 2010).

Conversion of cellulose to fermentable sugars is effective in sub-CW compared to in supercritical state (Olanrewaju, 2012). According to Phaiboonsilpa et al. (2010), lignocellulosics waste treated by hydrothermal method will lead to conversion of cellulose into glucose whereas hemicellulose into mannose and fructose. This technique is inexpensive, cleaner and using a non-toxic solvent as a medium for the conversion (Ravber et al., 2015; Tunchaiyaphum et al., 2013; Abdelmoez et al., 2011). Although there have been many studies employing sub-CW for the conversion of OPMF to valuable materials, the detailed changes of mesocarp fibre structure were never reported. Studies have shown that the conversion of oil palm waste to sugars and organic acids is possible via hydrolysis using sub-CW (Kurnin et al., 2016). Hence, in the present study, the transformation of mesocarp fibre when treated in water at subcritical state was observed visually using light microscope and scanning electron microscopy (SEM) and discussed according to the yielded products.

\section{MATERIAL AND METHODS}

\section{Material and Sample Preparation}

The sample of OPMF was prepared by manual peeling of mesocarp from oil palm fruits. The peeled mesocarp fibre was ground manually using mortar with a pestle until the sample obtained was in the form of a paste. The sample was kept in the freezer to prevent microbial growth. The moisture content was also tested using moisture analyser
(Denver instrument, Model IR 35) by placing $1 \mathrm{~g}$ of OPMF sample onto the designated sample plate. The sample was dried at $103^{\circ} \mathrm{C}$ for $16 \mathrm{~min}$ to obtain a constant weight reading.

\section{Methods}

Sub-CW reaction. Batch reactor made up of stainless steel (SUS316) with an internal diameter of $16.5 \mathrm{~mm}$ and length of $150.4 \mathrm{~mm}$ as shown in Figure 1 was used as the reactor for sub-CW treatment. Molten salt bath (Celsius $600 \mathrm{H}$, Tomasu Kagaku) was pre-heated between $200^{\circ} \mathrm{C}$ and $300^{\circ} \mathrm{C}$ until the desired temperature. OPMF sample, $0.5 \mathrm{~g}$ was placed into the reactor using a spatula and filled with distilled water in a sample $(\mathrm{g})$ to water $(\mathrm{g})$ ratio of 1:10. The reactor was purged with argon gas to expel the air present in the reactor. The reactor internal pressure was estimated from the saturated water vapour pressure-temperature table (Klein et al., 1985). The sample was collected in a tube and centrifuged (Kubota, 2410) at $4000 \mathrm{rpm}$ for $10 \mathrm{~min}$ to separate the content into three phases: the oil phase, aqueous phase and solid phase as shown in Figure 2.

Structural changes analysis. Structural changes of mesocarp fibre before and after the reaction was viewed using a light microscope (Olympus, CX23). Samples were viewed at different magnification for a better view on reaction effect on mesocarp fibre structure. The required amount of sample was placed on a slide and covered with a coverslip. Stain reagents such as iodine and methylene blue were added to identify regions present with carbohydrate and protein within the cell respectively. Image Acquisition program (LEICA Q-WIN) was used to capture the view of the sample under a light microscope with high magnification.

The surface morphology of OPMF samples was observed under SEM, model Hitachi S-3400N. The raw OPMF and solid samples were dried under $80^{\circ} \mathrm{C}$ for two days before they underwent SEM analysis which use electrons to form an image recorded at the magnification of 300-600X. The Zetasize (Malvern, Worcestershire, United Kingdom) was used to measure particle size from less than a nanometer to several microns using dynamic light scattering (DLS). Prior to each analysis, samples were oven-dried for $24 \mathrm{hr}$. The size was measured at $25^{\circ} \mathrm{C}$ as system temperature using 1.33 as dispersant refractive index and 0.1 as material absorbance.

Compositional changes analysis. The high performance liquid chromatography (HPLC) was used to determine the type and concentration of sugar present in the tested samples. By using the serial dilution technique, sugar solution with 
different concentration was prepared to obtain the calibration curve for cellobiose, xylose, glucose, fructose, and sucrose. For the pre-treatment, the aqueous samples were filtered and transferred to a smaller vial. Peak area and retention time obtained from samples' graph were recorded to identify the concentration of each component present in aqueous phase samples. Hexane was used as a medium to recover oil extracted after the reaction. The hexane-soluble component collected in the sample bottle was dried in the fume chamber and filtered before weighing it to determine oil yield. After the recovery of the oil phase from the sample, the centrifuge tubes were centrifuged again. Watersoluble component remained in the reactor was recovered by adding ultrapure water into the reactor tube. The content from the reactor tube was collected into a sample bottle using Pasteur pipette and ultrapure water was added until it reached 50 $\mathrm{ml}$. Calibration curve of the standard solution with $\mathrm{R}^{2}=0.9978$ value was used as a reference to identify the total sugars present in the aqueous sample obtained at different reaction temperatures. Ultra violet (UV) absorption spectrometer (Shimadzu, UV-1600) was used to measure the absorbance of the aqueous samples in the cuvette at $490 \mathrm{~nm}$. After the recovery process of the aqueous phase solution from samples, the reactor tube and the solid phase were dried at $80^{\circ} \mathrm{C}$. The solid phase content remained in test tubes were weighed to obtain the yield of residual solid. Yield of the solid residue and tar were determined by gravimetric analysis. The solid phase product collected after the reaction was added with acetone solution and filtration using cellulose acetate membrane filter was carried out to separate tar and solid residue.

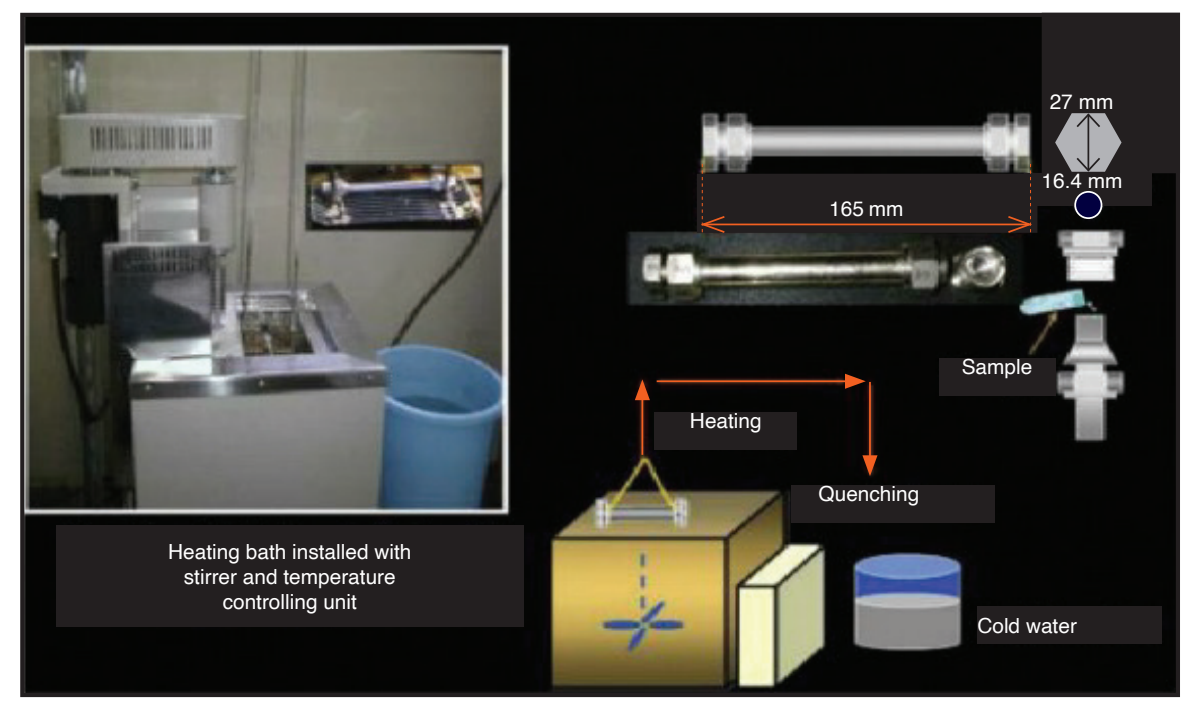

Source: Abdelmoez et al. (2014).

Figure 1. Set up of subcritical water (sub-CW) reaction system.

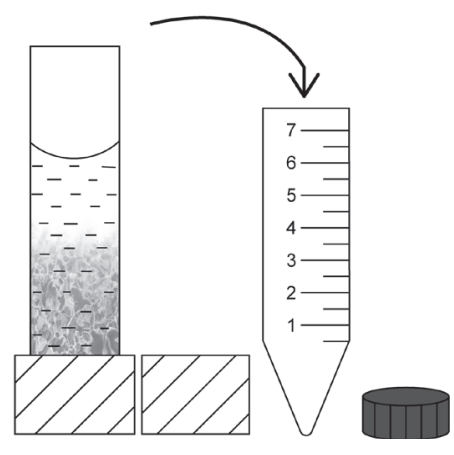

Sample after sub-CW reaction

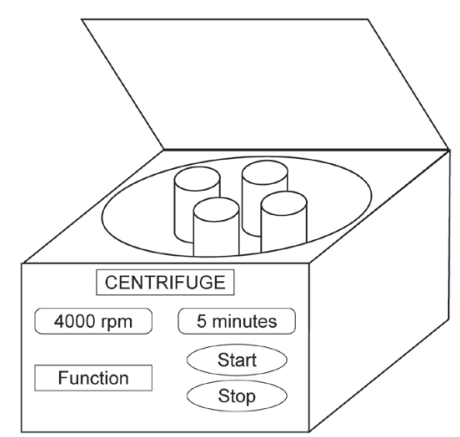

Sample after centrifuge at $4000 \mathrm{rpm}$

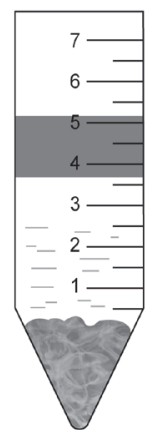

Sample separaterd into three different phases (oil, aqueous and solid)

Figure 2. Subcritical water (sub-CW) products phase separation method. 
RESULTS AND DISCUSSION

\section{Moisture Content}

The moisture content of OPMF showed an average value of $34.2 \%$ by drying the sample under moisture analyser at $103^{\circ} \mathrm{C}$ for $16 \mathrm{~min}$. However, moisture content determined from the conventional method of sample drying showed an average value of $33.0 \%$ which is almost similar to the value obtained using moisture analyser. According to Azis et al. (1990), the average moisture content of OPMF of ripe fruit from 20-30 weeks after anthesis is 30\%-40\%. The actual weight of the sample used for the reaction was determined by identifying the amount of water present in wet samples used throughout this study.

\section{Sub-CW Reaction}

Figure 3 shows the product obtained after sub-CW reaction. The product was centrifuged to separate into three phases with the oil phase at the top, the aqueous phase at the middle and the solid phase at the bottom of the centrifuge tube. The process of centrifugation separates the product into three different phases respective to their different density values [palm oil: $0.92 \mathrm{~g} \mathrm{~cm}^{-3}$ (Hodgman and Lange, 1924), distilled water: $1.00 \mathrm{~g} \mathrm{~cm}^{-3}$ and solid matters: $\left.6.38 \mathrm{~g} \mathrm{~cm}^{-3}\right]$. The density of the solid residue was calculated using the Equation (1):

$$
\underset{\left(\mathrm{g} \mathrm{cm}^{-3}\right)}{\text { Solid density }}=\frac{\frac{\text { weight }}{\text { volume of solid product }\left(\frac{\mathrm{g}}{\mathrm{cm}^{3}}\right)}}{1-\text { porosity }\left(\mathrm{cm}^{3}\right)}
$$

Equation (1)

The yellowish orange colour intensity of the aqueous phase of sub-CW reaction product decreased above the reaction temperature of $230^{\circ} \mathrm{C}$. This change is due to the palm oil losing its carotenoid content which then resulted in the reduction of colour intensity as the reaction temperature increased. This phenomenon agrees with the literature since the degradation of carotenoid content is significant at temperatures above $230^{\circ} \mathrm{C}$ (Sampaio, 2013).

\section{Structural Changes}

The plant cell walls of OPMF before sub$\mathrm{CW}$ reaction as shown in Figure 4. The cell wall was viewed under a light microscopic at 40X magnification. No plant cell walls and green pigmentations were visible in solid phase collected after sub-CW reaction due to the degradation of green pigmentation of OPMF when heat treatment was applied (Weemaes et al., 1999). Besides that, sub-CW reaction broke down the OPMF walls into smaller particles as seen in Figure 4. The solid product at reaction temperature of $200^{\circ} \mathrm{C}$ stuck to each other forming oily clump due to the presence of oil whereas the solid product at reaction temperature of $300^{\circ} \mathrm{C}$ was blackish due to the presence of tar formation. The solid samples were viewed under SEM to understand surface morphology of OPMF reacting in sub-CW. The solid product at reaction temperature of $200^{\circ} \mathrm{C}$ in Figure 5, had an oily and shiny surface due to the presence of oil similar to the untreated OPMF sample. The surface of the solid product at reaction temperature of $240^{\circ} \mathrm{C}$ shown in Figure 5 was occupied by open pores, which proved that the hydrolysis process disrupted the smooth surface of the sample. Hemicellulose acts as cross linker for cellulose and micro fibril was removed contributing to rougher surface and removal of silica left the surface with voids (Ariffin et al., 2008). Sub-CW acts as acid causing catalytic cleavage of glyosidic bond of hemicellulose. The presence of tar as the sample degraded at a reaction temperature higher than $250^{\circ} \mathrm{C}$ through the pyrolysis process caused the solid sample of $300^{\circ} \mathrm{C}$ to look dense as shown in Figure 5.

Figure 6 shows the effect of sub-CW temperature on the particle size of solid residue and its relation to the yield of sugar and yield of tar. Particle size was determined using DLS to measure movement of particles in liquid. The particle size collected after sub-CW as solid product was found increase with increase in reaction temperature. The particle size of solid product collected at reaction temperature

\begin{tabular}{llllllll}
\hline Temperature $\left({ }^{\circ} \mathrm{C}\right)$ & 200 & 210 & 220 & 230 & 240 & 250 & 260 \\
\hline \\
Centrifuged product
\end{tabular}

Note: Reaction time - 5 min.

Figure 3. Products obtained after subcritical water (sub-CW) reaction. 
of $200^{\circ} \mathrm{C}$ was $639.9 \mathrm{~d} . \mathrm{nm}$ whereas the particle size increased to $1358 \mathrm{~d} . \mathrm{nm}$ as the reaction temperature increased to $240^{\circ} \mathrm{C}$. The yield of total sugars in the water-soluble phase was the highest at around $240^{\circ} \mathrm{C}$. It is interesting note that the yield of sugars has the same trend as the particle size. The excellent relation of particle size trend with subCW temperature indicates that at high temperature, lignocellulose probably degrades and increases the hydrophobicity and thermal stability of solid content (Hosseinaei, 2012). Nordin et al. (2013) who studied the structural changes of OPMF treated with steam under superheated condition also reported that hemicellulose removal makes the fibre surface more hydrophobic. The particle size of the solid phase reduces as the reaction temperature higher than $240^{\circ} \mathrm{C}$ as the pyrolysis reaction take places (Pourali, 2010).
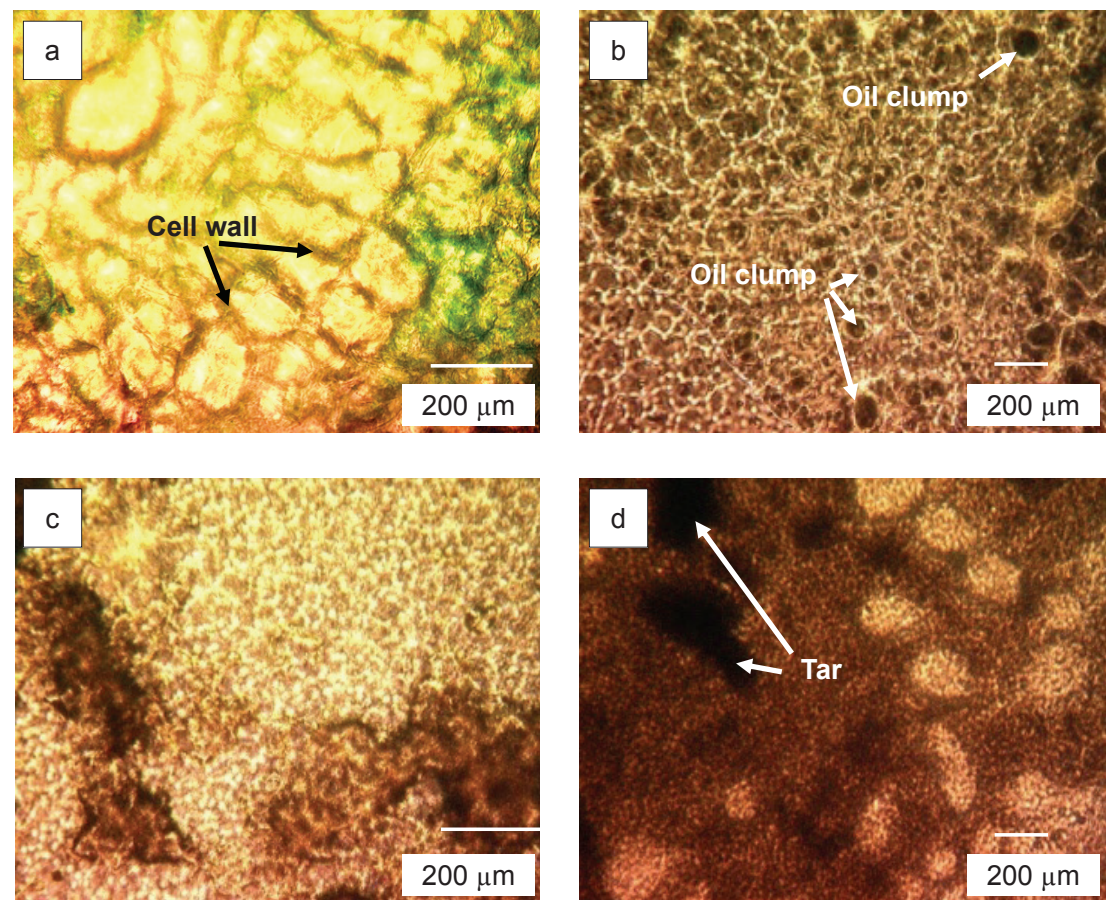

Figure 4. Microscopic view of fresh and subcritical water (sub-CW) treated oil palm mesocarp fibre (OPMF) at various temperatures. (a) Untreated, (b) $200^{\circ} \mathrm{C}$, (c) $240^{\circ} \mathrm{C}$ and (d) $300^{\circ} \mathrm{C}$.
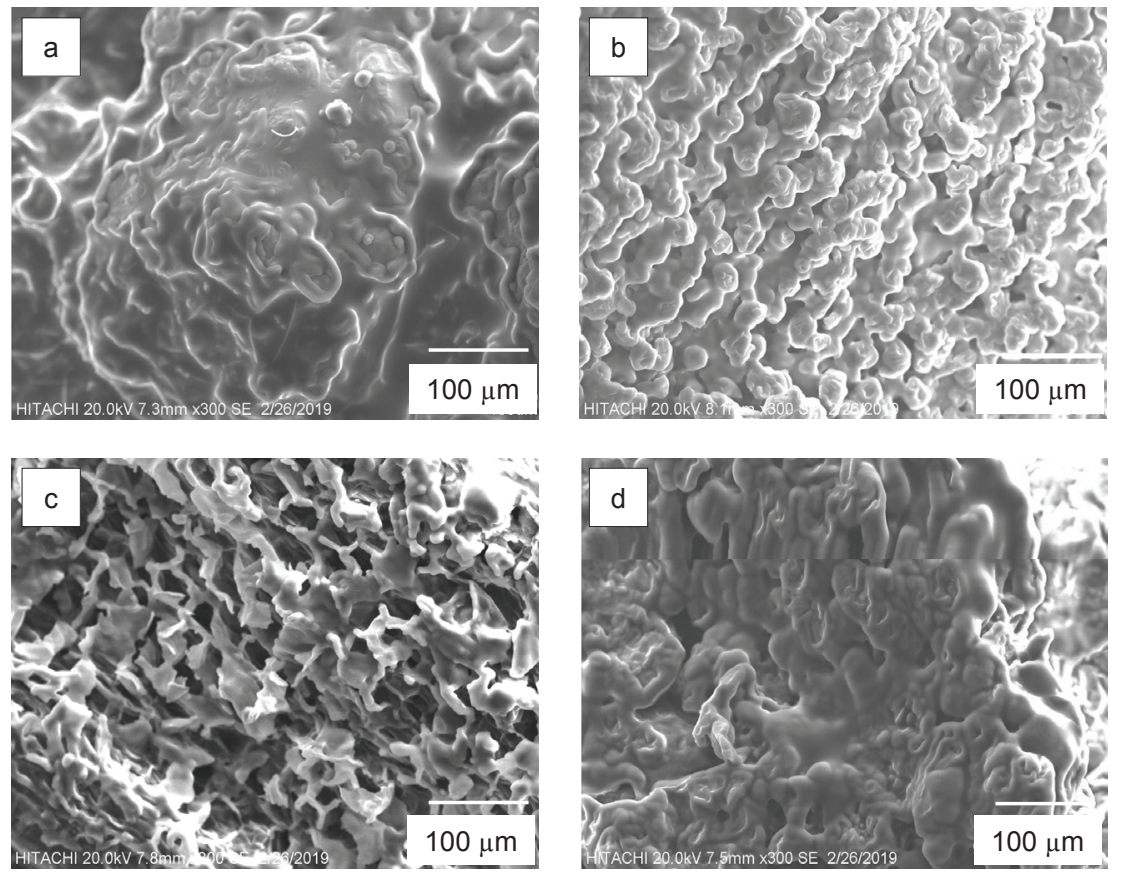

Figure 5. Scanning electron microscopy (SEM) images at 300X of subcritical water (sub-CW) treated oil palm mesocarp fibre (OPMF) at various temperatures. (a) Untreated, (b) $200^{\circ} \mathrm{C},(c) 240^{\circ} \mathrm{C}$ and (d) $300^{\circ} \mathrm{C}$. 


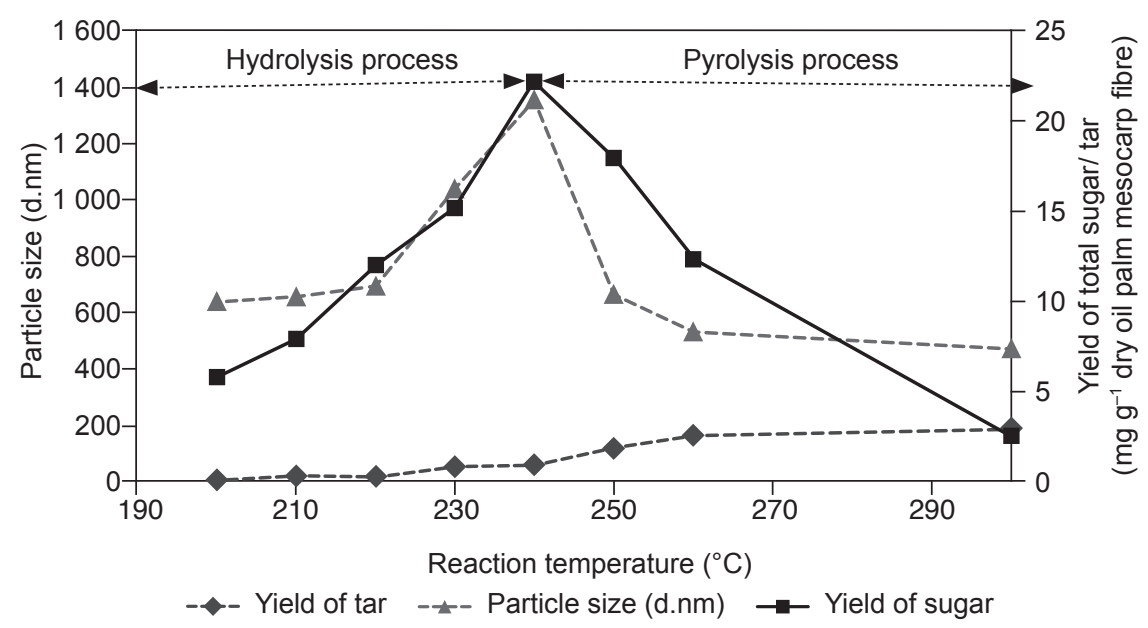

Figure 6. Effect of subcritical water (sub-CW) reaction temperature on particle size of solid residue and its relation to yield of sugar and yield of tar.

Meanwhile, tar formation obtained from the hardened solid residue kept increasing with increasing sub-CW temperature. Removal of hemicellulose into aqueous phase product was measured by the yield of sugars whereas the presence of tar as pyrolysis reaction product was also measured through the yield of tar.

This increase indicates that the tar formation during pyrolysis process has caused the solid phase to easily break due to its brittle characteristic.

\section{Compositional Changes}

HPLC (PU-2080 plus, Jasco Corp. Tokyo, Japan) with two size-exclusion chromatography columns in series (Shodex SUGAR KS-801 and KS-G, Shodex Co., Tokyo, Japan) using a refractive index detector (RI-2031 plus, Jasco Corp.) was used to determine the type and concentration of the sugars present. Figure 7 shows the effect of sub-CW temperature on the type and concentration of sugars where as Table 1 represent coefficient of limit of detection (LOD) and limit of quantitation (LOQ) of sugar content. At temperatures of $200^{\circ} \mathrm{C}$ and $220^{\circ} \mathrm{C}$, disaccharides such as cellobiose and sucrose were present with the total amount of $5.63 \mathrm{mg} \mathrm{g}^{-1}$-dry OPMF and $7.63 \mathrm{mg}$ $\mathrm{g}^{-1}$-dry OPMF, respectively. For the sample treated under sub-CW reaction at $240^{\circ} \mathrm{C}$ and $260^{\circ} \mathrm{C}$, glucose and fructose were present together with cellobiose and sucrose. Sub-CW having high ion production to act as solvent eased the hydrolysis process to occur. Monosaccharide was present as reaction temperature was increased to $240^{\circ} \mathrm{C}$. However, the yield of monosaccharides decreased from $6.27 \mathrm{mg} \mathrm{g}^{-1}$-dry OPMF to $1.99 \mathrm{mg} \mathrm{g}^{-1}$-dry OPMF as the reaction temperature increased to $260^{\circ} \mathrm{C}$ due to the degradation of sugar.

Figure 8 shows that the total amount of solid residue collected from the products decreased as the reaction temperature increased. The highest total amount of solid residue collected was at $190^{\circ} \mathrm{C}$ (5.77 $\mathrm{mg} \mathrm{g}^{-1}$-dry OPMF) whereas the lowest amount of solid residue collected was at $300^{\circ} \mathrm{C}(0.70 \mathrm{mg}$ $\mathrm{g}^{-1}$-dry OPMF). At the reaction temperature higher than $240^{\circ} \mathrm{C}$, the solid phase degraded the cellulose and hemicellulose present in the sample and produced tar as a by-product through pyrolysis reaction (Asadieraghi and Daud, 2014). The total weight of solid collected after sub-CW reaction reduced to $41.8 \%$ of its initial dry weight as the sample reacted at $240^{\circ} \mathrm{C}$. Yield of oil using Soxhlet extraction method was $0.033 \mathrm{~g} \mathrm{~g}^{-1}$-dry OPMF. Dielectric constant of water decrease as the temperature increase (Sarip et al., 2014). This will increase the solubility of oil in water and effect the sub-CW reaction which contribute to tar formation.

TABLE 1. COEFFICIENT OF LOQ AND LOD OF SUGAR CONTENT

\begin{tabular}{lcccc}
\hline Component & Calibration curve equation & $\mathbf{R}^{2}$ & LOD $(\mu \mathrm{g})$ & LOQ $(\mu \mathrm{g})$ \\
\hline Cellobiose & $\mathrm{y}=442.26 \mathrm{x}-81.288$ & 0.9990 & 1.2 & 3.6 \\
Sucrose & $\mathrm{y}=493.49 \mathrm{x}-7066.9$ & 0.9942 & 1.0 & 3.0 \\
Glucose & $\mathrm{y}=454.4 \mathrm{x}-1271.9$ & 0.9997 & 1.0 & 3.0 \\
Fructose & $\mathrm{y}=444.24 \mathrm{x}+955.97$ & 0.9998 & 1.2 & 3.6 \\
\hline
\end{tabular}

Note: LOD - limit of detection.

LOQ - limit of quantitation. 


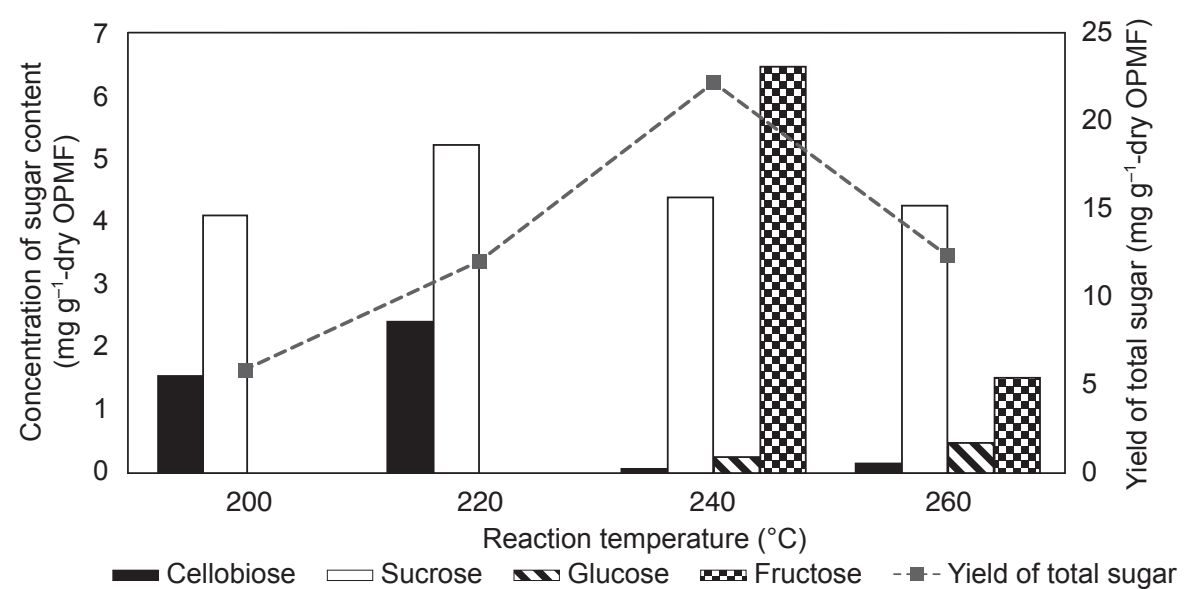

Note: OPMF - oil palm mesocorp fibre.

Figure 7. Effect of subcritical water (sub-CW) reaction temperature on type and concentration of sugars.

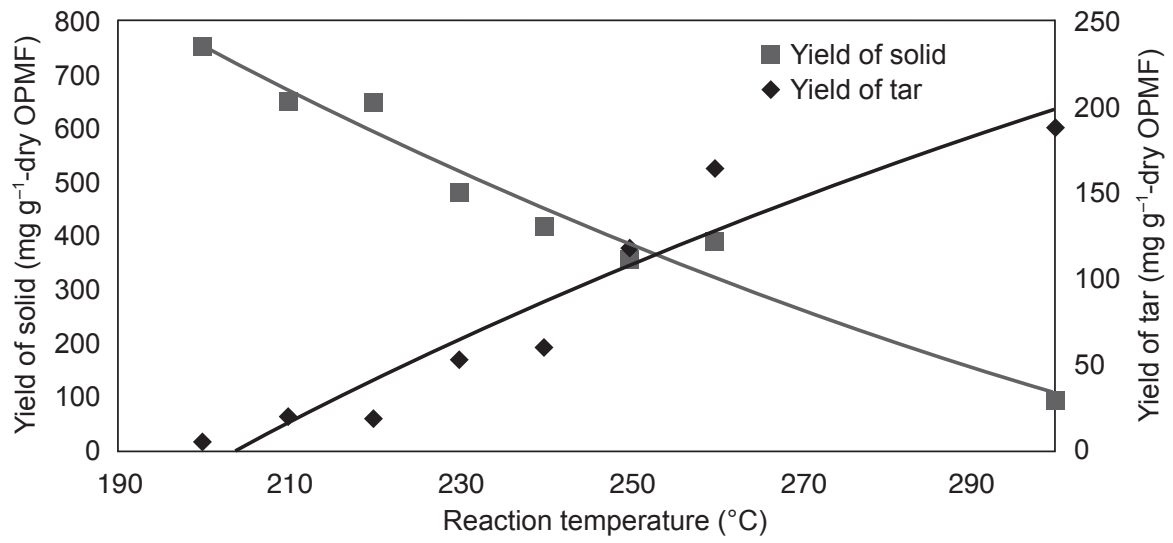

Note: OPMF - oil palm mesocorp fibre.

Figure 8. Effect of subcritical water (sub-CW) reaction temperature on yield of solid residue and yield of tar.

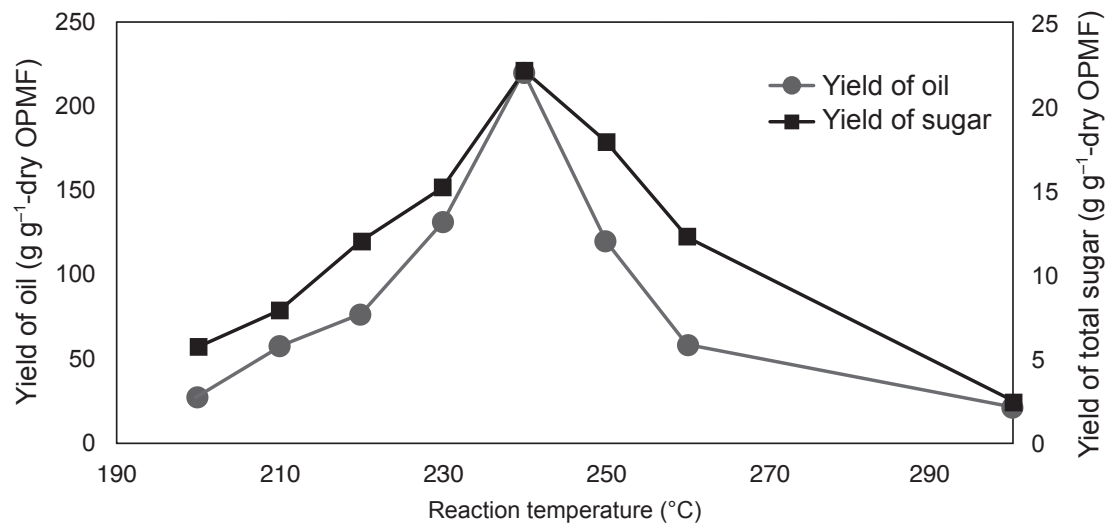

Note: OPMF - oil palm mesocorp fibre.

Figure 9. Effect of subcritical water (sub-CW) reaction temperature on yield of oil and yield of sugar.

\section{CONCLUSION}

Hydrothermal treatment processes on the oil palm mesocarp fibre using sub-CW reaction caused the plant cell wall in mesocarp fibres to be disrupted and weakened the fibre structure. Hydrolysis and pyrolysis reactions subsequently took place when OPMF was treated with sub-CW. Observations using SEM proved the structural changes of OPMF cell, which then yielded sugar and tar that were 
obtained at different reaction temperatures. At $250^{\circ} \mathrm{C}$, the ion production was at maximum due to strong hydrolysis reaction. However, above $250^{\circ} \mathrm{C}$, pyrolysis reaction took place and reduced the ion production drastically. Oil yield increased as the disrupted plant cell released oil droplet from it whereas breakdown cell walls in the form of monosaccharide contributed to the increase in the yield of total sugars. As shown in Figure 9, the optimum yield of sugars and oil obtained by sub$\mathrm{CW}$ at $240^{\circ} \mathrm{C}$ were $22.17 \mathrm{mg} \mathrm{g}^{-1}$-dry OPMF and 28.07 $\mathrm{mg} \mathrm{g}^{-1}$-dry OPMF, respectively. The increased yield was due to the ion production of water at $250^{\circ} \mathrm{C}$, but the decline in yield was a result of pyrolysis. Consequently, the amount of oil recovered, and sugar yield depended on reaction temperature as changes in water properties to act as acid and ease hydrolysis and pyrolysis reactions.

\section{ACKNOWLEDGEMENT}

The authors gratefully acknowledge the support of this work by the Malaysian government through Universiti Putra Malaysia Graduate Research Fund (GRF grant number 9491400).

\section{REFERENCES}

Abdelmoez, W; Abdelfatah, $\mathrm{R}$ and Tayeb, A (2011). Extraction of cottonseed oil using subcritical water technology. AIChE Journal, 57(9): 2353-2359.

Amashukeli, X; Pelletier, C C; Kirby, J P and Grunthaner, F J (2007). Subcritical water extraction of amino acids from Atacama Desert soils. J. Geophysical Res., (112): 1-10.

Ariffin, H; Hassan, M A; Umi Kalsom, M S; Abdullah, $N$ and Shirai, $Y$ (2008). Effect of physical, chemical and thermal pretreatments on the enzymatic hydrolysis of oil palm empty fruit bunch (OPEFB). J. Trop. Agric. Food Sci., 36: 259-268.

Asadieraghi, M and Daud, W M A W (2014). Characterization of lignocellulosic biomass thermal degradation and physiochemical structure: Effects of demineralization by diverse acid solutions. Energy Convers. Manag., 82: 71-82.

Azis, A; Rosnah, M S; Mohamadiah, B and Wan, Z (1990). Morphological changes of the cellular component of the developing palm fruit (Tenera: Elaeis guineensis). PORIM Bulletin No. 21: 30-34.
Carr, A G; Mammucari, R and Foster, N R (2011). A review of subcritical water as a solvent and its utilization for the processing of hydrophobic organic compounds. Chem. Eng. J., 172(1): 1-17.

Hodgman, C D and Lange, N A (1924). Handbook of Chemistry and Physics. Chemical Rubber Co., Ohio, USA. 1112 pp.

Hosseinaei, O; Wang, S; Enayati, A A and Rials, $T$ G (2012). Effects of hemicellulose extraction on properties of wood flour and wood-plastic composites. Compos. Part A Appl. Sci. Manuf., 43(4): 686-694.

Iberahim, N I; Jahim, J M; Harun, S; Nor, M T M and Hassan, O (2013). Sodium hydroxide pretreatment and enzymatic hydrolysis of oil palm mesocarp fibre. Int. J. Chem. Eng. Appl., 4(3): 101105.

Kalsom, U MS; Ariff, A B; Shamsuddin, Z H; Tong, C C; Hassan, M A and Karim, M I A (1997). Production of cellulase by a wild strain of Chaetomium globosum using delignified oil palm empty-fruit-bunch fibre as substrate. Appl. Microbiol. Biotechnol., 47(5): 590595.

Klein, S A and Alvarado, F L (1998). Appendix 1: Property table and charts (SI unit). Thermodynamics. p. 883-932.

Kurnin, N A A; Ismail, M H S; Yoshida, $\mathrm{H}$ and Izhar, S (2016). Recovery of palm oil and valuable material from oil palm empty fruit bunch by subcritical water. J. Oleo Sci., 65 (4): 283-289.

Lau, H L N; Choo, Y M; Ma, A N and Chuah, C $H$ (2008). Selective extraction of palm carotene and vitamin E from fresh palm-pressed mesocarp fibre (Elaeis guineensis) using supercritical $\mathrm{CO}_{2}$. J. Food Eng., 84(2): 289-296.

National Innovation Agency Malaysia (2013). National Biomass Strategy 2020: New Wealth Creation for Malaysia's Palm Oil Industry. Version 2.0. National Innovation Agency Malaysia. 37 pp.

Nordin, N I; Ariffin, H; Andou, Y; Hassan, M A; Shirai, Y; Nishida, H; Yunus, W Z; Karuppuchamy, $S$ and Ibrahim, N A (2013). Modification of oil palm mesocarp fibre characteristics using superheated steam treatment. Molecules, 18(8): 9132-9146.

Olanrewaju, K B (2012). Reaction Kinetics of Cellulose Hydrolysis in Subcritical and Supercritical Water. Ph.D thesis, University of Iowa, USA. 242 pp. 
Phaiboonsilpa, N; Yamauchi, K; Lu, X and Saka, S (2010). Two-step hydrolysis of Japanese cedar as treated by semi-flow hot-compressed water. J. Wood Science, 56(4): 331-338.

Pourali, O (2010). Production of Valuable Materials From Rice Bran Biomass Using Subcritical Water. Ph.D thesis. Osaka Prefecture University, Japan. 131 pp.

Pourali, O; Salak, F and Yoshida, H (2009). Simultaneous rice bran oil stabilization and extraction using sub-critical water medium. J. Food Eng., 95(3): 510-516.

Ravber, M; Knez, Ž and Škerget, M (2015). Simultaneous extraction of oil- and water-soluble phase from sunflower seeds with subcritical water. Food Chem., (166): 316-323.

Sampaio, K A; Ayala, J V; Silva, S M; Ceriani, R; Verhé, R and Meirelles, A J (2013). Thermal degradation kinetics of carotenoids in palm oil. $J$. Amer. Oil Chem. Soc., 90(2): 191-198.

Sarip, M S M; Morad, N A; Ali, N A M; Yusof, Y A M and Yunus, M A C (2014). The kinetics of extraction of the medicinal ginger bioactive compounds using hot compressed water. Separation and Purification Technology, 124: 141-147.

Sarip, M S M; Morad, N A; Yamashita, Y; Tsuji, T; Yunus, M A C; Aziz, M K A and Lam, H L (2016). Crude palm oil (CPO) extraction using hot compressed water (HCW). Separation and Purification Technology, 169: 103-112.

Singh, P P and Saldaña, M D A (2011). Subcritical water extraction of phenolic compounds from potato peel. Food Res. Int., 44(8): 2452-2458.
Sreekala, M S; Kumaran, M G and Thomas, S (1997). Oil palm fibres: Morphology, chemical composition, surface modification, and mechanical properties. J. Appl. Polym. Sci., 66: 821-835.

Then, Y Y; Ibrahim, N A; Zainuddin, N; Ariffin, H; Yunus, W M Z W and Chieng, B W (2014). Surface modifications of oil palm mesocarp fibre by superheated steam, alkali and superheated steamalkali for biocomposite applications. Bioresources, 9(4): 7467-7483.

Tunchaiyaphum, S; Eshtiaghi, M N and Yoswathana, N (2013). Extraction of bioactive compounds from mango peels using green technology. Int. J. Chem. Eng. Appl., 4(4): 194-198.

Teoh, C H (2002). The Palm Oil Industry in Malaysia: From Seed to Frying Pan. WWF Malaysia. http:/ / d2ouvy59p0dg6k.cloudfront.net / downloads / oilpalmchainpartaandb_esri.pdf, accessed on 22 January 2019. 88 pp.

Weemaes, C A; Ooms, V; Van Loey, A M and Hendrickx, M E (1999). Kinetics of chlorophyll degradation and color loss in heated broccoli juice. J. Agric. Food Chem., 47(6): 2404-2409.

Yoshida, H; Izhar S; Nishio E, Utsumi Y; Kakimori $\mathrm{N}$ and Feridoun, S A (2018). Application of sub-critical water for recovery of tin and glass substrates from LCD panel e-waste. Detritus, 4: 98103.

Yunos, N S H M; Baharuddin, A S; Yunos, K F M; Naim, M N and Nishida, H (2012). Physicochemical property changes of oil palm mesocarp fibers treated with high-pressure steam. BioResources, 7(4): 5983-5994. 